\title{
Submaximal exercise thallium-201 SPECT for assessment of interventional therapy in patients with acute myocardial infarction
}

\begin{abstract}
Submaximal thallium-201 stress testing has been shown to provide important diagnostic and prognostic information in patients with acute myocardial infarction. The purpose of this investigation was to evaluate the diagnostic value of early submaximal stress testing and thallium-201 single photon emission computed tomography (SPECT) after interventional therapy. Scintigraphic results from 56 patients with infarctions, who underwent acute thrombolytic therapy, angioplasty, or both, were compared with late (6 weeks) functional outcome as assessed by radionuclide ventriculography and with results of discharge coronary angiography. A linear correlation was found between the extent of thallium-201 SPECT perfusion defect and late ventricular function $(r=0.74, p<0.01)$. Forty-two percent of patients with large SPECT perfusion defects had normal left ventricular ejection fractions, suggesting an overestimation of infarct size by early imaging. Sensitivity and specificity of thallium-201 SPECT for detection of coronary artery stenosis in noninfarct territories was $57 \%$ and $46 \%$, respectively, indicating limited diagnostic definition of extent of underlying coronary artery disease. Results of follow-up coronary angiography showed a significant relationship between the size of the initial perfusion defect and early restenosis or reocclusion of the infarct artery. Thus the extent of early thallium-201 perfusion defects correlates with late functional outcome but appears to overestimate the degree of injury. Submaximal thallium-201 stress testing allows only limited characterization of underlying coronary artery disease. Early assessment of infarct size may identify a patient population at high risk for reocclusion of the infarct artery. (AM HEART J 1991;121:1033.)
\end{abstract}

Richard E. Stewart, MD, Nathan Kander, MD, Jack E. Juni, MD, Stephen G. Ellis, MD, William W. O’Neill, MD, M. Anthony Schork, PhD, Eric J. Topol, MD, and Markus Schwaiger, MD. Ann Arbor, Mich.

With the wide acceptance of intravenous thrombolytic therapy as the treatment of choice in patients with acute myocardial infarction, the need for noninvasive methods to evaluate the success of such therapy is being increasingly appreciated. Infarct

From the Divisions of Nuclear Medicine and Cardiology and the School of Public Health, Department of Internal Medicine, University of Michigan Medical Center.

Supported by an established investigatorship from the American Heart Association (Dr. Schwaiger).

Received for publication Aug. 6, 1990; accepted Sept. 17, 1990.

Reprint requests: Markus Schwaiger, MD, University of Michigan Medical Center, UH BI G505, Box 0028, 1500 E. Medical Center Dr., Ann Arbor, MI 48109-0028.

4/1/26968 size, extent of underlying coronary artery disease, and patency of the infarct artery determine shortand long-term prognosis in patients with acute infarction. ${ }^{1}$ Thallium-201 stress testing has been shown to provide valuable prognostic information in patients with myocardial infarction who have not been treated with interventional therapy. ${ }^{2,3}$ Little clinical data, however, are available to assess the prognostic value of submaximal exercise thallium201 stress testing after interventional therapy.

Thallium-201 has been used via the intracoronary route for the early assessment of salvaged myocardium. ${ }^{4,5}$ The early distribution of thallium- 201 in reperfused myocardium has been shown to be principally related to blood flow. 6,7 Based on these 
experimental results, thallium-201 imaging is expected to allow early delineation of irreversibly injured myocardium after thrombolytic therapy. However, several clinical reports indicate that thallium-201 imaging may overestimate the extent of myocardial scarring in chronic infarction, as evidenced by improvement in function and perfusion after revascularization of these segments. ${ }^{8,9}$ Thus, the role of early thallium-201 imaging for the assessment of infarct size after thrombolytic therapy is not yet clearly defined. Aside from the assessment of infarct size, the detection of myocardium at risk is important for risk stratification in patients with acute infarction. ${ }^{10}$ Thallium-201 single photon emission computed tomography (SPECT) has been shown to provide high diagnostic accuracy for localization of disease by use of maximal stress. ${ }^{2}$ However, the diagnostic value of submaximal exercise thallium201 SPECT in patients who have undergone thrombolytic therapy needs further definition.

The sustained patency of the infarct-related artery has been shown to be beneficial for tissue recovery, ${ }^{11}$ but the mechanisms responsible for early restenosis and reocclusion after successful thrombolytic therapy are poorly understood. Besides local thrombogenic factors, reduced coronary blood flow in large infarcted areas may contribute to restenosis and reocclusion of the infarct artery. The purpose of this study, therefore, was to retrospectively assess the predictive value of early submaximal thallium-201 SPECT for late functional outcome and extent of underlying coronary artery disease in patients receiving acute intervention with thrombolytic therapy, percutaneous transluminal coronary angioplasty (PTCA), or both. In addition, the relationship between restenosis of the infarct artery and the extent of myocardial perfusion abnormalities was assessed to define the possible effect of reduced tissue perfusion on restenosis and reocclusion of the infarct artery.

\section{METHODS}

Study patients. The study group comprised 56 survivors of acute myocardial infarction, 51 men and five women, aged 29 to 76 (mean 54) years. Fifty-three patients received intravenous recombinant tissue plasminogen activator ( $\mathrm{rt}$ PA) a mean of 2.7 hours (range 30 minutes to 6 hours) after the onset of symptoms. Acute ( $\leq 1$ day) coronary angiography was performed in all patients. Forty-two patients underwent acute coronary angioplasty at the time of initial catheterization in addition to receiving thrombolytic therapy, whereas three patients were treated with acute coronary angioplasty alone. All patients underwent early exercise thallium-201 SPECT, follow-up predischarge cardiac catheterization, and equilibrium radionuclide ventriculography between 3 and 6 weeks after the acute event.
None of the patients had a prior history of myocardial infarction in the same coronary distribution.

Diagnosis of acute myocardial infarction. Diagnosis was based on characteristic ECG changes and/or serum creatine kinase levels $(>225 \mathrm{IU} / \mathrm{L})$, and $\mathrm{MB}\left(>3 \%_{\circ}\right)$ fraction levels (ACA, Du Pont Pharmaceuticals, Wilmington, Del.). Blood samples were drawn every 6 hours for the first 18 hours of hospitalization and once every 8 hours during the next day. The results of the thallium-201 SPECT studies were not used to establish the diagnosis of myocardial infarction.

Cardiac catheterization and acute intervention. Intravenous rt-PA was administered in a dose of $1.0 \mathrm{mg} / \mathrm{kg}$ body weight ( $90 \mathrm{mg}$ maximum) over the first hour. The remainder of the dose (120 to $150 \mathrm{mg}$ ) was infused over the next 5 to 6 hours. ${ }^{12}$ At the 90 -minute point in rt-PA infusion, coronary angiography was performed. The infarct artery was identified both visually and by correlation with $\mathrm{ST}$ segment changes on the ECG. Acute coronary angioplasty was used for all patients whose infarct artery had failed to recanalize within 90 minutes after the initiation of rt-PA infusion and for those patients randomly selected to undergo this procedure. ${ }^{13}$ All patients received concomitant heparin, aspirin, and diltiazem therapy for at least 1 week, starting from the time of hospital admission.

Repeat coronary angiography was performed a mean of 10 days (range 7 to 20 days) after the acute event. Cineangiographic films were analyzed with the investigators unaware of the results of noninvasive testing. Infarct vessel patency was defined as clinical TIMI grade 2 or 3 , whereas failure to reperfuse was considered clinical TIMI grade 0 to $1 .{ }^{14}$ The severity of a coronary artery stenosis was expressed as a percentage of the luminal diameter as assessed by two experienced catheterization laboratory physicians in at least three oblique views for the left coronary artery and two views for the right coronary and circumflex arteries. Early restenosis was defined as an immediate postangioplasty stenosis diameter of less than $50 \%$, increasing to $\geq 70 \%$ at follow-up. ${ }^{15}$

Thallium-201 SPECT. Studies were carried out in each patient between 3 and 9 days (mean of 5 days) after myocardial infarction with treadmill stress testing and a mod ified Bruce protocol. Exercise tolerance was expressed as a pressure-rate product (PRP) (peak systolic blood pressure $\times$ peak heart rate $\div 100=P R P)$. Sixty seconds before the termination of submaximal treadmill stress (heart rate $\leq 130$ beats $/ \mathrm{min}, \mathrm{PRP} \leq 250$ ), $3.0 \mathrm{mCi}$ of thallium-201 chloride (Du Pont NEN, Du Pont Diagnostic Imaging Division, North Billerica, Mass.) was administered intravenously. Thallium-201 SPECT images were acquired with a General Electric 400AT Maxicamera system (GE Medical Systems, Milwaukee, Wis.). Image acquisition was accomplished in a 180-degree arc, 64 projections at 15 seconds each. Delayed images were obtained 3 to 4 hours later. Filtered backprojection was accomplished with a Siemens microdelta computer (Siemens Medical Systems, Inc, South Iselin, N.J.) with a Butterworth filter. Thallium-201 myocardial uptake was scored visually by two independent observers, blind to clinical information, from three tomo- 


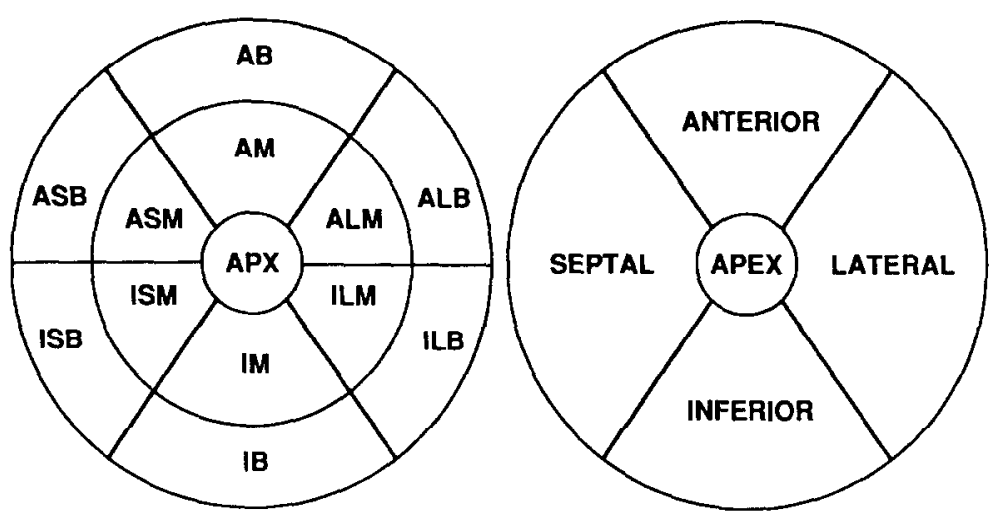

Fig. 1. "Bulls eye" representation of 13 myocardial scoring segments (left). $A B$, anterior basal; $A M$, anterior mid; $I M$, inferior mid; $I B$, inferior basal; $A S B$, anteroseptal basal; $I S B$, inferoseptal basal; $A S M$, anteroseptal mid; $I S M$, inferoseptal mid; $A L B$, anterolateral basal; $I L B$, inferolateral basal; $A L M$, anterolateral mid; $I L M$, inferolateral mid; $A P X$, apex. Consolidated scoring segments (right) used to compare thallium-201 SPECT perfusion scores with late radionuclide ventriculography.

graphic views (oblique, sagittal, and coronal). Thirteen myocardial segments per study were derived from the three tomographic views and were graded (Fig. 1). Each segment was scored as follows: $0=$ absent uptake, $1=$ moderate decrease, $2=$ mild decrease, and $3=$ normal thallium-201 uptake. The maximal score for a normal thallium-201 SPECT study was 39 . Redistribution was defined as an increase from stress to delayed image of one scoring unit in at least one segment. To compare thallium-201 SPECT perfusion defects with regional wall motion analysis, the 13 scoring segments were combined into 5 regions (anterior $=2$ segments, inferior $=2$ segments, septum $=4$ segments, lateral $=4$ segments, and apex $=1$ segment). A total of 1456 myocardial segments were evaluated and combined into 560 scoring segments for thallium-201 SPECT perfusion defects from stress and delayed images. Results of these studies were then correlated with coronary angiography data from the day of admission. Vascular territories corresponding to thallium-201 SPECT regions included the left anterior descending artery (which encompassed the anterior, apical, and septal regions), the right coronary artery (corresponding to the inferior regions), and the left circumflex artery (corresponding to the lateral region).

Equilibrium radionuclide ventriculography. Gated equilibrium studies at rest were performed in all patients a mean of 45 days (range 20 to 62 days) after acute myocardial infarction. A 10-inch gamma scintillation camera (General Electric data camera system, standard field of view; GE Medical Systems, Milwaukee, Wis.) equipped with a low-energy, high-sensitivity, parallel-hole collimator was used. Ejection fractions were obtained as described previously. ${ }^{16}$ Regional wall motion in five segments (anterior, inferior, lateral, septum, and apex) was assessed by two independent observers and scored as follows: $3=$ normal, 2 = moderate hypokinesis, $1=$ severe hypokinesis, $0=$ akinesis, and $-1=$ dyskinesis.

Statistical analysis. Values are expressed as mean \pm 1
SD. A two-tailed $p$ value $<0.05$ was considered significant. Statistical methods include chi-square contingency table analysis to test whether pairs of categorical variables were associated, analysis of variance to assess whether the means of continuous variables differed for various factors, and stepwise regression analysis to develop predictive models for certain variables. These stepwise analyses included both normal errors (for continuous variables) and logistic models (for dichotomous variables).

\section{RESULTS}

Patient characteristics. All 56 patients in the study had a clinical presentation and ECG changes consistent with acute myocardial infarction. Fifty-three patients had serum creatine kinase levels $\geq 225$ IU/L on serial enzyme assays. The incidence of single-vessel disease was $45 \%$ (25 of 56 patients), whereas $55 \%$ of patients had multivessel disease $(20$ of 56 patients [ $36 \%$ ] had two-vessel disease; 11 of 56 patients [19\%] had three-vessel disease). Fifty-four patients $(96 \%)$ had abnormal results of thallium-201 SPECT studies. The patients were divided into three groups based on the extent of the infarct as reflected by 3 - to 4 -hour postexercise (or delayed) thallium201 SPECT perfusion scores. Twenty-nine percent ( $n=16$ ) of patients in the study population (group 1) had thallium-201 SPECT perfusion scores $\geq 37$, representing a perfusion defect equal to 0 to 1 scoring segment (normal and "mild" perfusion defects). Group $2(n=21)$ comprised patients with "moderate" perfusion defects equivalent to between 1 and 2 scoring segments, representing $37 \%$ of the study population. The other $34 \%$ of study patients with "severe" defects were in group $3(n=19)$, with perfusion scores $<33$. Two patients received the maximal "normal" score of 39 on both exercise and 3-hour 


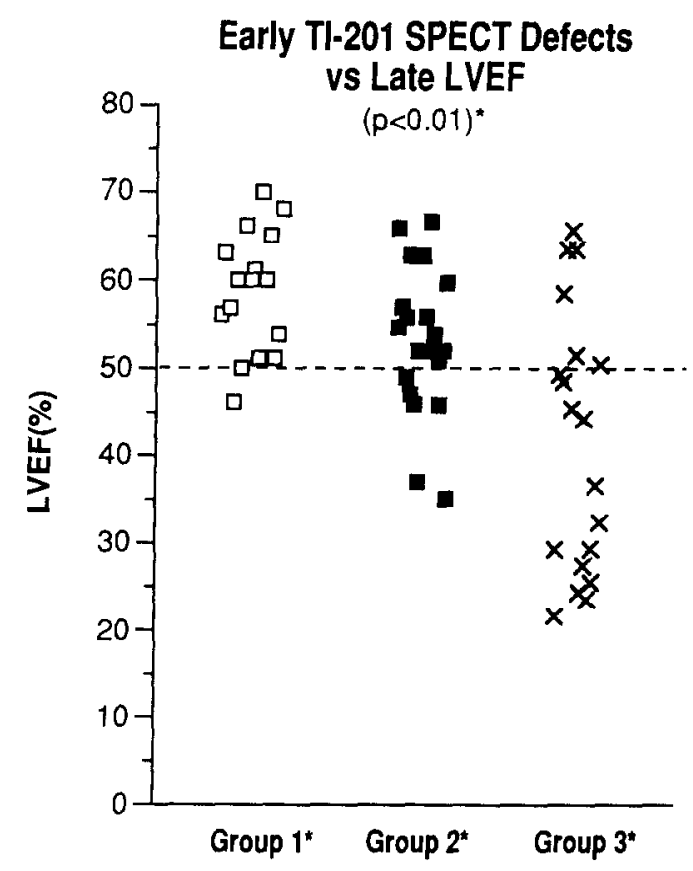

Fig. 2. Late follow-up radionuclide left ventricular ejection fractions $(L V E F)$ for patient groups. $\square$, group $1 ; \square$, group $2 ; \mathrm{X}$, group $3 ; \mathrm{p}<0.01$ between all groups. Broken line (- - ) represents normal ejection fraction limit at our institution.

delayed thallium-201 SPECT studies and were included in group 1. Exercise tolerance did not differ significantly among patient groups according to PRP criteria ( $229 \pm 42$ for group $1,200 \pm 46$ for group 2 , and $193 \pm 40$ for group $3 ; p=\mathrm{NS}$ ). As expected there were significant differences in peak serum creatine kinase levels between all three patient groups $(1297 \pm 1441 \mathrm{IU} / \mathrm{L} \quad$ vs $2632 \pm 1360 \quad \mathrm{IU} / \mathrm{L}$ vs $3774 \pm 2603 \mathrm{IU} / \mathrm{L} ; p<0.05$ among all groups). Sixty-two percent of patients in group $1,75 \%$ of patients in group 2 , and $84 \%$ of patients in group 3 underwent acute coronary angioplasty ( $p=\mathrm{NS}$ ). Of the three patients who underwent acute angioplasty alone, one was in group 2 and two were in group 3 . Patient characteristics are summarized in Tables I and II.

Thallium-201 SPECT results and late ventricular function. Global left ventricular function at rest, as assessed by late radionuclide ventriculography ejection fraction, was significantly different between patients in groups 1 and $2(59 \% \pm 7 \%$ vs $53 \% \pm 8 \%$; $p<0.05)$ and between patients in groups 1 and 3 $(59 \% \pm 7 \%$ vs $42 \% \pm 14 \% ; p<0.01)$ (Fig. 2). A linear correlation was observed between the resting left ventricular ejection fraction and the thallium201 SPECT perfusion score on both submaximal exercise $(r=0.75, p<0.01)$ and delayed $(r=0.74$, $p<0.01$ ) SPECT studies (Fig. 3). Eight patients $(42 \%)$ in group 3 (severe thallium-201 SPECT perfusion defects), however, had a normal ( $\geq 50 \%$ ) left ventricular ejection fraction on late follow-up. Average wall motion scores were $2.7 \pm 0.7$ for group 1 , $24 \pm 0.9$ for group 2 , and $1.8 \pm 1.0$ for group 3 (Table III).

Comparison of reversible and fixed thallium-201 SPECT perfusion defects. Thallium-201 SPECT perfusion defects that exhibited complete reversibility were present in $62 \%$ of patients in group $1,14 \%$ in group 2 , and only $5 \%$ in group 3 ( $p<0.05$ among the three groups). As expected, $96 \%$ of patients with wall motion abnormalities in their infarct-related artery regions on late radionuclide ventriculograms had a fixed component to their early thallium-201 SPECT studies, reflecting nonviable (or a mixture of viable and nonviable) myocardium.

Early submaximal exercise thallium-201 SPECT and extent of coronary artery disease. Significant additional coronary artery disease was defined as a luminal stenosis of more than $50 \%$ on follow-up coronary angiography. The sensitivity of early thallium-201 SPECT in detecting coronary artery disease in the infarct artery related myocardial regions was $96 \%$. In the noninfarct artery regions of 31 patients with multivessel coronary artery disease, sensitivity was $57 \%$ and specificity was $46 \%$, yielding a positive predictive value of $55 \%$ and a negative predictive value of $48 \%$. In patients with single-vessel left anterior descending coronary artery disease $(<50 \%$ stenosis elsewhere), thallium-201 SPECT defects were falsely detected in the inferior wall region in 6 of 18 patients $(33 \%)$ and in the lateral myocardial region in 1 of 18 patients $(6 \%)$. Likewise in cases of single-vessel right or circumflex coronary artery disease, 6 of $38(16 \%)$ patients had thallium-201 SPECT perfusion defects detected in the anterior wall.

Early thallium-201 SPECT perfusion defects versus early infarct artery restenosis and reocclusion. Twenty-five percent of patients in the study group had early restenosis or reocclusion of the infarct artery. Average residual stenosis of the infarct artery, after administration of rt-PA (with and without coronary angioplasty), was $47 \% \pm 27 \%$ for group 1 , $34 \% \pm 17 \%$ for group 2 , and $35 \% \pm 13 \%$ for group $3(p=N S)$. Average stenosis on follow-up angiography was $40 \% \pm 27 \%$ for group 1 ( $p=$ NS vs early angiography), $57 \% \pm 32 \%$ for group $2(p<0.01$ vs early angiography), and $72 \%+27 \%$ for group 3 ( $p<0.01$ vs early angiography) (Fig. 4). The incidence of early restenosis and reocclusion in an initially opened infarct artery was significantly higher $(p<0.05)$ among patients in group 3 with more extensive thallium-201 SPECT perfusion defects $(53 \%)$ compared with each of groups $1(0 \%)$ and $2(19 \%)$ (Fig. 5). Three patients in group $2(14 \%)$ and five patients in group $3(26 \%)$ had complete occlusion on follow-up coronary angiography. In all patients with 

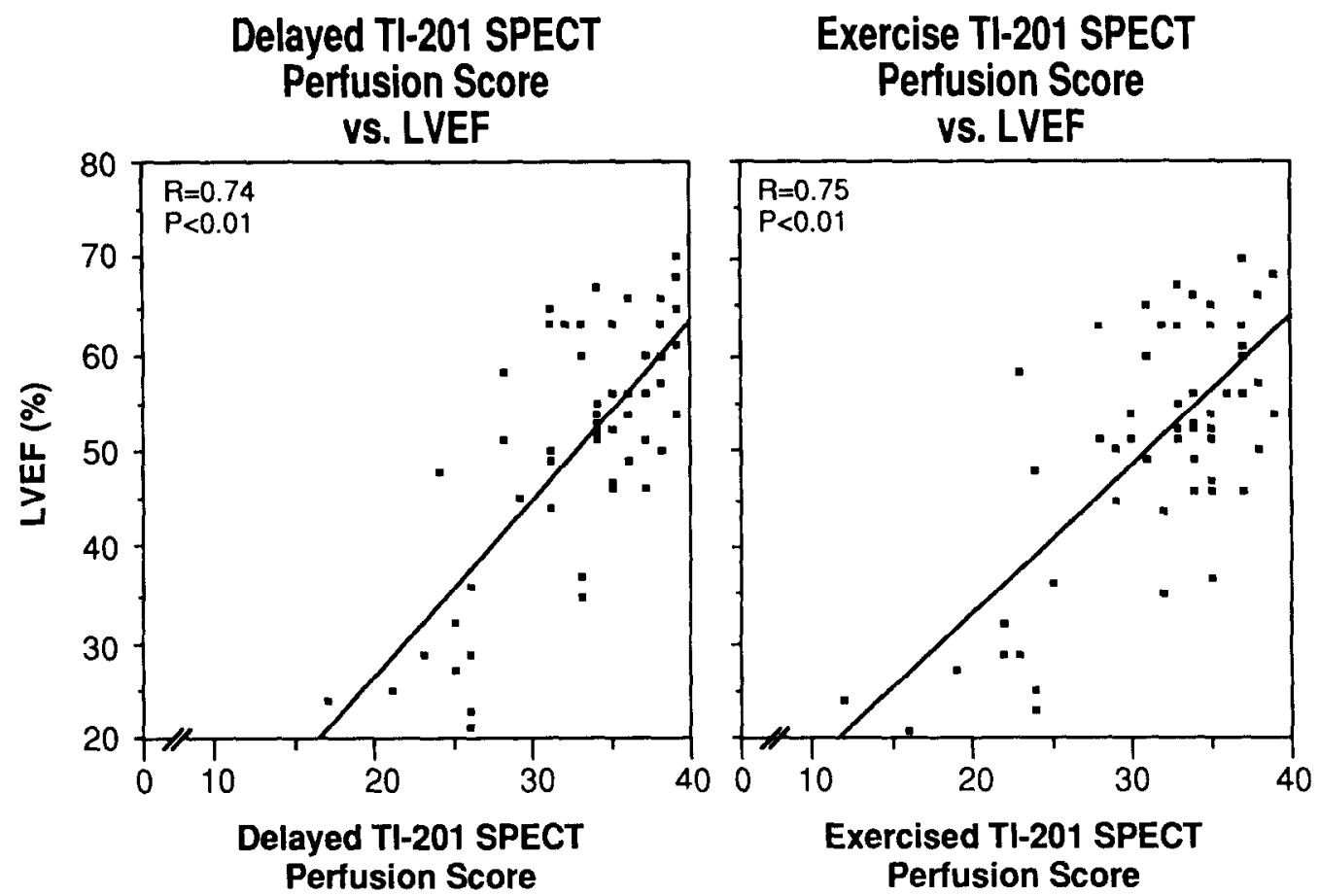

Fig. 3. Correlation between radionuclide left ventricular ejection fraction ( $L V E F)$ and 3-hour delayed (left) and immediate post-submaximal exercise (right) thallium-201 SPECT perfusion scores. Maximal thallium-201 SPECT score $=39$.

Table I. Characteristics of patients in study groups on day of admission for acute myocardial infarction

\begin{tabular}{|c|c|c|c|c|c|c|c|c|}
\hline $\begin{array}{l}\text { Patient } \\
\text { group }\end{array}$ & $n$ & $\begin{array}{l}\text { Age } \\
(y r)\end{array}$ & Sex & $\begin{array}{c}\text { Prior history } \\
\text { of } M I \\
\text { No. of patients }\end{array}$ & $\begin{array}{c}\text { Location } \\
\text { of } A M I\end{array}$ & $\begin{array}{c}\text { No. of } \\
\text { diseased } \\
\text { vessels }\end{array}$ & $\begin{array}{c}\text { Time* symptoms } \\
\text { to rt-PA (hr) }\end{array}$ & $\begin{array}{c}\text { Peakt CPK } \\
(I U / L)\end{array}$ \\
\hline 1 & 16 & $58 \pm 8$ & $\begin{aligned} 15 \mathrm{M} \\
1 \mathrm{~F}\end{aligned}$ & 0 & $\begin{array}{r}14 \mathrm{inf} \\
2 \mathrm{ant}\end{array}$ & $\begin{array}{rr}10 & 1 \\
4 & 2 \\
2 & 3\end{array}$ & $2.5 \pm 1.0$ & $1,297 \pm 1,441$ \\
\hline 2 & 21 & $53 \pm 11$ & $\begin{array}{c}18 \mathrm{M} \\
3 \mathrm{~F}\end{array}$ & 2 & $\begin{array}{r}17 \text { inf } \\
2 \text { ant }\end{array}$ & $\begin{array}{ll}6 & 1 \\
9 & 2 \\
6 & 3\end{array}$ & $2.7 \pm 1.2$ & $2,632 \pm 1,360$ \\
\hline 3 & 19 & $54 \pm 7$ & $\begin{array}{c}18 \mathrm{M} \\
1 \mathrm{~F}\end{array}$ & 4 & $\begin{array}{l}7 \mathrm{inf} \\
12 \text { ant }\end{array}$ & $\begin{array}{ll}9 & 1 \\
7 & 2 \\
3 & 3\end{array}$ & $3.1 \pm 1.5$ & $3,774 \pm 2,603$ \\
\hline
\end{tabular}

AMI, acute myocardial infarction; Inf, inferior wall; ant, anterior wall; CPK, serum creatine kinase levels.

${ }^{*} p=\mathrm{NS}$.

$\dagger_{p}=<0.05$ among all groups.

early restenosis and reocclusion, events occurred more frequently in the right coronary artery $(71 \%)$, when it was identified as the infarct artery, as compared with the left anterior descending artery (29\%). Fighty-three percent of patients with restenosis and reocclusion were treated initially with acute coronary angioplasty in addition to thrombolytic therapy.

Stepwise logistic regression analysis showed that significant predictors of early restenosis of the infarct artery included extent of thallium-201 SPECT perfusion defect, both on stress and delayed studies, and time from the onset of symptoms to the administra-
Table II. Thallium-201 SPECT perfusion scores and performance data from three groups of patients

\begin{tabular}{|c|c|c|c|}
\hline $\begin{array}{c}\text { Patient } \\
\text { group }\end{array}$ & $\begin{array}{c}\text { TI-20I SPECT* } \\
\text { Exercise } \\
\text { perfusion score } \\
\text { (max score }=39)\end{array}$ & $\begin{array}{c}\text { TI-201 SPECT* } \\
\text { Delayed } \\
\text { perfusion score } \\
(\max \text { score }=39)\end{array}$ & $\begin{array}{c}\text { Exerciset } \\
\text { tolerance } \\
\quad(P R P)\end{array}$ \\
\hline 1 & $36.7 \pm 1.6$ & $37.8 \pm 0.9$ & $229+42$ \\
\hline 2 & $33.5 \pm 1.8$ & $34.5 \pm 1.0$ & $200 \pm 46$ \\
\hline 3 & $25.2 \pm 5.4$ & $27.4 \pm 4.8$ & $193 \pm 52$ \\
\hline
\end{tabular}

PRP, pressure-rate product.

${ }^{*} \mathrm{p}<0.001$ among all groups.

$+p=$ NS. 


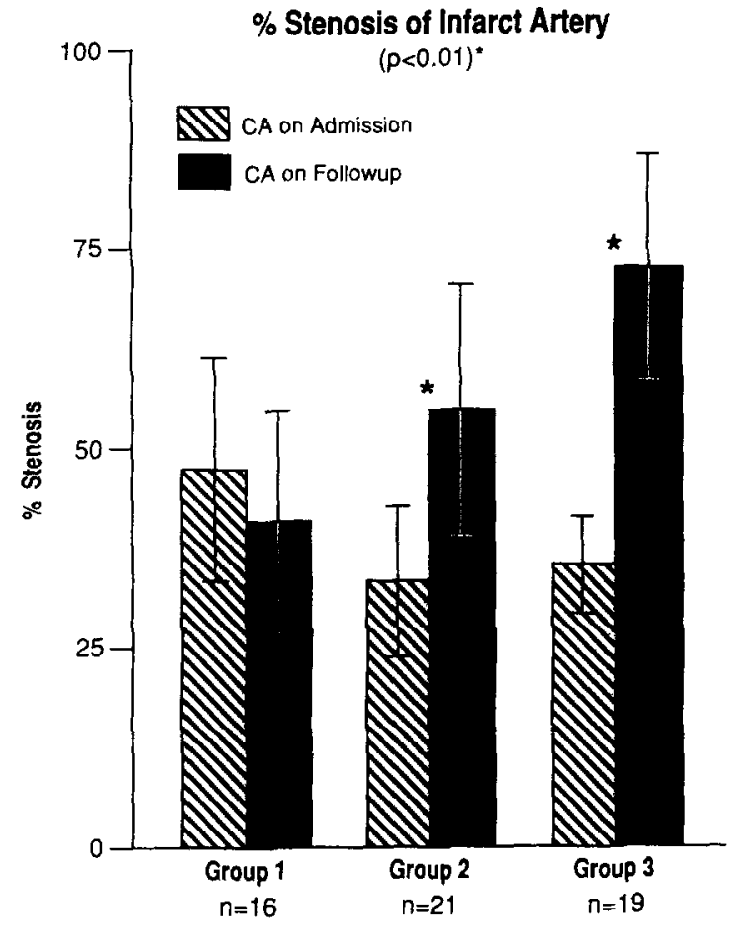

Fig. 4. Comparison between percentage of stenosis of infarct artery on admission $(\mathbb{N})$ and follow-up coronary angiography $(\boldsymbol{\square}) . C A$, coronary angiography. $p<0.01$ between admission and follow-up $\mathrm{CA}$ in groups 2 and 3.

tion of thrombolytic therapy (Table IV). The percentage of residual stenosis of the infarct artery after acute intervention at the time of hospital admission, the reversibility of thallium-201 SPECT perfusion defects, peak serum creatine kinase levels, and treatment with acute coronary angioplasty were not significant relative predictors of early restenosis, although peak serum creatine kinase levels did correlate directly when considered independently $(p<0.05)$.

\section{DISCUSSION}

Early noninvasive assessment of the extent of the infarct and underlying coronary artery disease, in patients undergoing thrombolytic therapy for acute myocardial infarction, is not only important for prognostic reasons but vital in directing subsequent clinical management. The present study compared both functional and angiographic outcomes with results of early submaximal exercise thallium-201 SPECT in a patient cohort treated acutely with intravenous rt-PA and PTCA.

Assessment of infarct size and tissue viability. Differentiation of viable and necrotic tissue early after a myocardial ischemic injury is difficult because

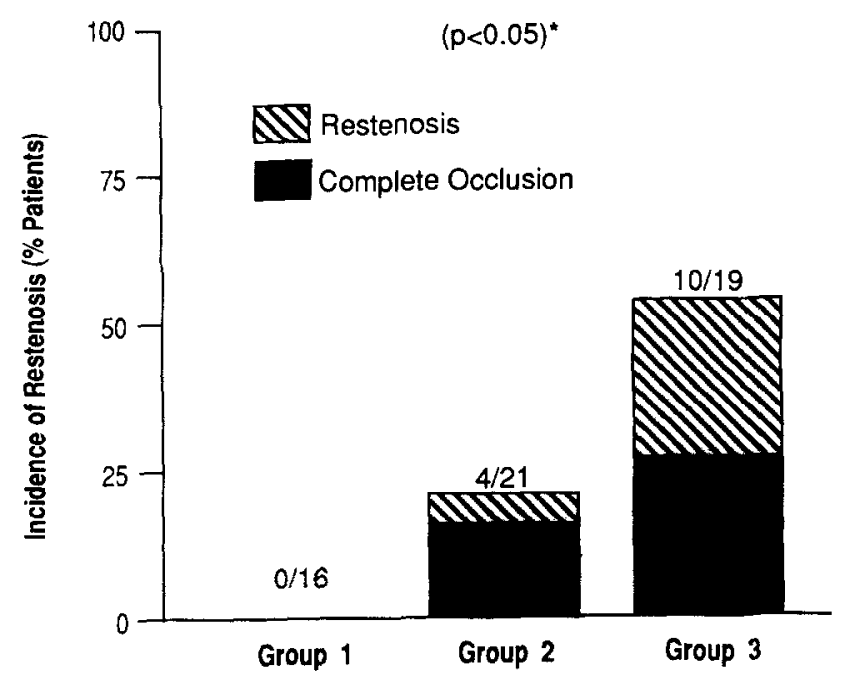

Fig. 5. Comparison between incidence of early restenosis and reocclusion in patient groups. Percentage of patients with restenosis; and $\boldsymbol{E}$, percentage of patients with complete occlusion. $p<0.05$ between group 3 and group 1 , and group 3 and group 2.

of the coexistence of reversible and irreversible myocardial dysfunction. Since myocardial retention of thallium is related to tissue viability, thallium-201 SPEC $T$ imaging is expected to provide a noninvasive means to delineate viable and necrotic myocardium. However, results of clinical studies indicate that "fixed" thallium-201 defects overestimate the extent of scar tissue in patients with previous myocardial infarction, ${ }^{17}$ thereby underestimating viable tissue in the infarct zone. This study was designed to define the relationship of thallium-201 SPECT results obtained early after thrombolytic therapy with late functional outcome as assessed by resting radionuclide ventriculography. There was a significant correlation between persistent thallium-201 SPECT defects, left ventricular ejection fraction, and persistent wall motion abnormalities, indicating the predictive value of this test for determining the extent of the infarct. This particularly applies to patients with small thallium-201 SPECT defects (group 1); $94 \%$ of patients in this group had a follow-up left ventricular ejection fraction in the normal range (Fig. 2). Thus thallium-201 SPECT allows early identification of patients with small infarcts in a low-clinical risk group, confirming recent data on the safety of early discharge of patients with acute myocardial infarction but normal results of thallium-201 SPECT studies. ${ }^{18}$

On the other hand, patients with large thallium201 SPECT defects (group 3) had significantly lower ejection fractions on late radionuclide ventriculogra- 
phy, indicating the predictive value of early thallium201 SPECT in assessment of final infarct size in these patients. However, $42 \%$ of these patients in group 3 had ejection fractions in the normal range (Fig. 2). These data are in agreement with the overestimation of infarct size observed in patients with chronic infarction. ${ }^{8,9}$ There was no significant relationship between redistribution of thallium-201 SPECT defects and preservation of late functional outcome in patients in group 3 since only $25 \%$ of patients with normal ejection fractions had reversible defects. This confirms that the presence of fixed thallium-201 SPECT defects does not exclude viability of residual tissue in infarcted territories. Metabolic imaging with positron emission tomography has been shown to provide improved detection of viable myocardium and may be required in patients with large persistent thallium-201 SPECT defects after thrombolytic therapy for the acute definition of irreversible tissue injury..$^{19}$ Independent of the possible overestimation of infarct size in individual patients, large thallium201 SPECT defects are related to poor functional outcome and larger enzymatic infarct size. Thus early thallium-201 SPECT can identify patients with poor functional outcome who are at risk for subsequent cardiac morbidity and mortality. ${ }^{20}$

Definition of extent of underlying coronary artery disease. Besides infarct size, the extent of angiographically defined coronary artery disease is an important determinant of long-term outcome. ${ }^{21}$ With the availability of medical and surgical revascularization, early identification of myocardium at risk is desirable. ${ }^{22}$ Although the predictive value of submaximal stress testing for subsequent cardiac complications has been demonstrated in numerous studies, data on the diagnostic value of submaximal stress thallium201 SPECT in the detection of significant coronary artery disease is less established. The data obtained in this study indicate a markedly lower diagnostic accuracy of submaximal thallium-201 SPECT imaging for localization of disease, as compared to standard maximal thallium-201 SPECT stress testing in patients with stable chronic coronary artery disease. ${ }^{23}$ This low sensitivity may be explained primarily by the lower work loads achievable early after infarction. In contrast to our data, Gibson et al. ${ }^{24}$ demonstrated a higher diagnostic accuracy in postinfarction patients, but with exercise testing and thallium-201 scintigraphy performed 11 days after infarction.

Our data are in agreement with recent work by Burns et al., ${ }^{25}$ which showed sensitivities of less than $40 \%$ in noninfarct territories from early symptomlimited exercise thallium-201 SPECT after acute
Table III. Wall motion scores (on follow-up radionuclide ventriculography) between study groups

\begin{tabular}{cccc}
$\begin{array}{c}\text { Patient } \\
\text { group }\end{array}$ & $\begin{array}{c}\text { LVEF } \\
(\%)\end{array}$ & $\begin{array}{c}\text { No. of } \\
\text { segments } \\
\text { evaluated }\end{array}$ & $\begin{array}{c}\text { Average† } \\
\text { WMS }\end{array}$ \\
\hline 1 & $59 \pm 7$ & 160 & $2.7 \pm 0.7$ \\
2 & $53 \pm 8$ & 210 & $2.4 \pm 0.9$ \\
3 & $41 \pm 14$ & 190 & $1.8 \pm 1.0$ \\
\hline
\end{tabular}

LVEF, left ventricular ejection fraction; WMA, wall motion abnormality; IA, infarct artery; WMS, wall motion score; see text for scoring system. ${ }^{*} p<0.01$ among all groups.

$+p<0.01$ for group 3 vs group $1 ; p<0.05$ for group 3 vs group 2 .

Table IV. Predictors of early restenosis and reocclusion of infarct artery

\begin{tabular}{lc}
\hline & $p$ \\
\hline${ }^{*}$ TI-201 SPECT perfusion score (exercise) & $<0.01$ \\
${ }^{*}$ TI-201 SPECT perfusion score (delayed) & $<0.01$ \\
Time of ischemia & $<0.01$ \\
Peak serum CPK & NS \\
Reversibility of thallium-201 perfusion defect & NS \\
Percentage of residual stenosis of infarct artery & NS \\
\hline
\end{tabular}

CPK, creatine phosphokinase; NS, not significant.

*Significant by stepwise logistic regression analysis.

myocardial infarction. Our specificity of only $46 \%$ may reflect the difficulty in separating vascular territories, especially in the case of large infarctions. This becomes evident, in our study population, in the high incidence of inferior wall defects in patients with single-vessel disease (33\% and $37 \%$ with the left anterior descending and left circumflex as the infarct artery, respectively). Difficulty in interpreting inferior wall defects on thallium-201 SPECT is a wellrecognized problem. ${ }^{26}$ Thus it is difficult to predict the extent of disease accurately after myocardial infarction with early submaximal exercise thallium-201 SPECT. Initial data obtained with the use of intravenous dipyridamole in this clinical setting indicate improved diagnostic accuracy. ${ }^{27}$ Dipyridamole may be the preferred mode of stress in this patient population because it does not require physical exercise, produces maximal coronary vasodilatation, and is well tolerated as early as 3 days after myocardial infarction. ${ }^{28}$

Relationship between thallium-201 SPECT perfusion defects and early infarct artery restenosis. A problem associated with thrombolysis is development of early coronary restenosis and reocclusion, which may be associated with recurrent myocardial ischemia, infarction extension, and mortality. Restenosis of the infarct artery may reflect a different pathophysiology from restenosis after elective angioplasty. Acute oc- 
clusion of a coronary artery in the setting of myocardial infarction is thought to result from plaque rupture and superimposed acute thrombocyte aggregation. ${ }^{29,30}$ Multiple factors have been thought to influence early restenosis and reocclusion after thrombolytic therapy and coronary angioplasty. ${ }^{29-32}$ Persistent activation of platelets and residual fibrin deposits are associated with rethrombosis. ${ }^{32}$ Thrombolytic agents have often been unable to completely lyse the entire thrombus by the time of emergent angioplasty. ${ }^{29,30}$ The inability of these agents to prevent and possibly promote continued activation of platelets and fibrinogen may lead to early restenosis through rethrombosis. Elevation of plasma thromboxane levels resulting from treatment with intravenous rt-PA is another possible mechanism through which this can occur. ${ }^{33}$ Finally, intraplaque hemorrhage resulting from acute coronary angioplasty may contribute to reocclusion of the infarct vessel.

The overall incidence of early restenosis and reocclusion in our patient population was $25 \%$ at the time of follow-up cardiac catheterization, which was slightly higher than restenosis rates reported by Sherry ${ }^{34}$ in postinfarction patients early after thrombolytic therapy ( $20 \%)$. The higher rates of right coronary artery restenosis and reocclusion found in our study population are similar to results seen by Bates et al., ${ }^{35}$ who observed that $65 \%$ of restenoses occurred in the right coronary artery in a subgroup of patients in the TAMI trial. There was a significant difference in the incidence of restenosis among patients with more extensive thallium-201 SPECT perfusion defects on delayed studies compared with patients with smaller defects $(0 \%$ vs $19 \%$ vs $53 \%$ for groups 1, 2, and 3, respectively; $p<0.05$ among all groups). These findings suggest the importance of coronary flow characteristics for patency of infarctrelated arteries. Many of the local factors mentioned previously, which influence early restenosis and reocclusion, may in turn be influenced by changes in coronary artery hemodynamics. This would result in lower coronary blood flow in areas of large myocardial infarcts as evidenced by extensive thallium-201 SPECT defects. Thus, the potential for thrombus formation may be increased. Results of experimental studies by Kloner and Alker ${ }^{36}$ showed sustained reductions in blood flow (as determined by radiolabeled microspheres) to the infarcted myocardial layers after 3 hours of coronary artery occlusion in dogs (non-reflow phenomena). Johnson et al. ${ }^{37}$ have shown a good correlation between extent of infarct in all three myocardial layers and the decline in vascular conductance during maximal vasodilatation in the open-chested porcine model of myocardial reperfu- sion. It is speculated that reduced regional blood flow, in conjunction with such factors as elevated plasma thromboxane levels after administration of rt-PA, may facilitate the interaction of platelets and the vessel wall and promote deposition on exposed surfaces causing restenosis or reocclusion of the coronary artery.

Methologic considerations. Thallium-201 SPECT studies were performed several days after acute coronary angiography. Therefore, extrapolation of the scintigraphic data (defect size) to the time of early catheterization may be limited. The question arises, however, whether the higher incidence of restenosis in group 3 may actually cause the thallium-201 SPECT results obtained several days after the initial angiography. This may be the case in some instances but is unlikely for all patients in group 3 with restenosis and reocclusion. This is supported by the fact that $85 \%$ of restenosis and reocclusion was clinically silent in our study population, indicating the existence of myocardial necrosis related to the initial clinical event.

Coronary angiograms were evaluated visually, which may limit the accuracy of the angiographic data. However, two experienced cardiologists reviewed the data, ensuring consistency in interpretation of data. In addition, the observed changes in lumen diameter among patients in group 3 clearly exceeded the degree of variation expected by possible intra- and interobserver variability.

Conclusions and clinical implications. Our results in patients receiving interventional therapy after acute myocardial infarction show that early submaximal exercise thallium-201 SPECT can define the extent of tissue injury in the infarct artery related myocardial regions but is limited in diagnosing the extent of coronary artery disease in postinfarction patients. In cases of small early thallium-201 SPECT perfusion defects, the test accurately predicted late functional outcome, as assessed by follow-up radionuclide ventriculography. Large thallium-201 SPECT perfusion defects, however, tend to overestimate the extent of late functional impairment. Advanced imaging modalities such as positron emission tomography may be superior in defining tissue viability in this patient population. Finally, the extent of thallium-201 SPECT perfusion defects in both stress and delayed studies is a significant predictor of early restenosis and reocclusion of the infarct artery. The identification of patients at high risk for restenosis and reocclusion of infarct-related arteries after acute intervention may contribute clinical information valuable in selecting those who might benefit from further invasive therapeutic procedures. 
We thank Vi Rhodes, Wanda J. Wysor, and Debbie Helterbridle for their expert help in the preparation of this manuscript.

\section{REFERENCES}

1. Kaul S, Lilly DR, Gascho JA. Prognostic utility of the exercise thallium-201 test in ambulatory patients with chest pain: comparison with cardiac catheterization. Circulation 1988; 77:745-58.

2. Brown KA, Weiss R, Clements JP, Wackers FJ. Usefulness of residual ischemic myocardium within prior infarct zone for identifying patients at high risk later after myocardial infarction. Am J Cardiol 1987;60:15-19.

3. Wijns W, Serruys PW, Simoons ML, et al. Predictive value of early maximal exercise test and thallium scintigraphy after successful percutancous transluminal coronary angioplasty. Br Heart J 1985;53:194-200.

4. Maddahi J, Ganz W, Ninomye K, et al. Myocardial salvage by intracoronary thrombolysis in evolving myocardial infarction: evaluation using intracoronary injection of thallium-201. AM HEART J 1981;102:664-74.

5. Markis JE, Malagold M, Parker JA, et al. Myocardial salvage after intracoronary thrombolysis with streptokinase in acute myocardial infarction: assessment by intracoronary thallium. 201. N Engl J Med 1981;305:777-85.

6. Forman R, Kirk ES. Thallium-201 accumulation during reperfusion of ischemic myocardium: dependence on regional blood flow rather than viability. Am J Cardiol 1984;54:659-663.

7. Schofer J, Mathey DG, Montz R, Bleifeld W, Stritzke P. Use of dual intracoronary scintigraphy with thallium-201 and technetium-99m dysophosphate to predict improvement in left ventricular wall motion immediately after intracoronary thrombolysis in acute myocardial infarction. $\mathrm{J}$ Am Coll Cardiol 1983;2:737-44.

8. Clonninger KG, DePuey EG, Berger HJ, et al. Incomplete redistribution in delayed thallium-201 single photon ernission computed tomography (SPECT) images: an overestimation of myocardial scanning. J Am Coll Cardiol 1988;12:955-63.

9. Ritchie JL, Albso PC, Caldwell JH, Trobaugh GB, Hamilton GW. Thallium-201 myocardial imaging: a comparison of the redistribution and rest images. J Nucl Med 1979;20:477-83.

10. Touchstone DA, Beller GA, Nygoard TW, Watson DD, Tedesco C, Kaul S. Functional significance of predischarge exercise thallium-201 findings following intravenous streptokinase therapy during acute myocardial infarction. AM HEART J 1988;116:1500-7.

11. Califf RM. Myocardial reperfusion: is it ever too late? .I Am Coll Cardiol 1989;13:1130-2.

12. Topol EJ, Califf RM, Kereiakes DJ, George BS. Thrombolysis and angioplasty in myocardial infarction (TAMI) trial. $\mathrm{J}$ Am Coll Cardiol 1987;10:65B-74B

13. Topol EJ, O'Neill WW, Langburd AB, et al. A randomized, placebo controlled trial of intravenous recombinant tissue type plasminogen activator and emergency coronary angioplasty in patient acute myocardial infarction. Circulation $1987 ; 75: 420-8$.

14. The TIMI Study Group. The thrombolysis in myocardial infarction (TIMI) trial. N Engl J Med 1985;312:932-6.

15. Serruys PW, Luijten $\mathrm{HE}$, Beatt $\mathrm{KJ}$, et al. Incidence of restenosis after successful coronary angioplasty: a time related phenomenon. Circulation 1988;77:361-71.

16. Borer JS, Kent KM, Bacharach SL, et al. Sensitivity, specificity and predictive accuracy of radionuclide cineangiography during exercise in patients with coronary artery disease: comparison with exercise electrocardiography. Circulation 1979; $60: 572-80$.

17. Brunken $R$, Schwaiger $M$, Grover-McKay $M$, Phelps $M$, Tillisch J, Schelbert HR. Positron emission tomography detects tissue metabolic activity in myocardial segments with persistent thallium perfusion defects. J $\Lambda \mathrm{m}$ Coll Cardiol $1987 ; 10: 557-67$
18. Topol EJ, Burek K, O'Neill WW, et al. A randomized controlled trial of hospital discharge three days after myocardial infarction. N Engl J Med 1988;318:1083-8.

19. Schwaiger M, Brunken R, Grover-McKay M, et al. Regional myocardial metabolism in patients with acute myocardial infarction assessed by positron emission tomography. J Am Coll Cardiol 1986;8:800-8.

20. Murray DP, Murray RG, Rafigi E, Littler WA. Routine exercise testing or thallium-201 scintigraphy for prediction of cardiac events post MI. Eur J Nuci Med 1987;3:274-7.

21. Gibson RS, Watson DD, Craddock GB, et al. Prediction of cardiac events after uncomplicated myocardial infarction: prospective study comparing predischarge thallium-201 scintigraphy and coronary angiography. Circulation 1983;68:32136.

22. Topol EJ, Ellis SG, George BS, et al. The pivotal role of multivessel coronary artery disease and the remote zone in the reperfusion era [Abstract]. J Am Coll Cardiol 1989;13:92A.

23. DePasquale EE, Nody AC, DePuey EG, et al. Quantitative rotational thallium-201 tomography for identifying and localizing coronary artery disease. Circulation 1988;77:316-27.

24. Gibson RS, 'I'aylor GT', Beller GA, et al. Predicting the extent and location of coronary artery disease during the early postinfarction period by quantitative thallium-201 scintigraphy. Am d Cardiol 1981;47:1010-19.

25. Burns RJ, Freeman MR, Liu P, et al. Limitation of exercise thallium single photon tomography early after myocardial infarction [Abstract]. J Am Coll Cardiol 1989;13:125A.

26. Esquerre JP, Coca FJ, Mortinez SJ, Guirand RF. Prone decubitus: a solution to inferior wall attenuation in thallium-201 myocardial tomography. J Nucl Med 1989;30:398-401.

27. Aaronson KA, Gacioch GM, Topol EJ, Schwaiger M. Comparison of dipyridamole 201-TI-SPECT with exercise RNV for the detection of jeopardized myocardium following thrombolytic therapy for acute myocardial infarction [Abstract]. $J$ Nucl Med 1989;30:862.

28. Leppo JA, O'Brien J, Rothendler JA, Getchell JD, Lee VW. Dipyridamole-thallium-201 scintigraphy in the prediction of future cardiac events after acute myocardial infarction. $\mathrm{N}$ Engl J Med 1984;301:1014-18.

29. Fuster V, Stein B, Halperin JL, Chesebro JH. Antithrombotic therapy in cardiac disease: an approach based on pathogenesis and risk stratification. Am J Cardiol 1990;65:38C-44C.

30. Stein B, Fuster V. Antithrombotic therapy in acute myocardial infarction: prevention of venous, left ventricular and coronary artery thromboembolism. Am J Cardiol 1989;64:33B$40 \mathrm{~B}$.

31. Black AJR, Anderson HV, Roubin GS, Powelson SW, Douglas JS, King SB. Repeat coronary angioplasty: correlates of a second restenosis. J Am Coll Cardiol 1988;11:714-18.

32. Simonton CA, Mark DB, Hinohara T, et al. Late restenosis after coronary angioplasty for acute myocardial infarction: comparison with elective coronary angioplasty. J Am Coll Cardiol 1988;11:698-705.

33. Shebuski RJ, Bloom JC, Sellers TS, et al. Attenuation of inhibitory effect of prostacyclins on platelet function after rt-PA or streptokinase infusion. Fibrinolysis 1989;3:115-23.

34. Sherry S. Appraisal of various thrombolytic agents in the treatment of acute myocardial infarction. Am J Med 1987; 83:31-46.

35. Bates ER, Califf RM, Stack RS, et al. Thrombolysis and Angioplasty in Myocardial Infarction (TAMI-1) trial: influence of infarct location on arterial potency, left ventricular function and mortality. J Am Coll Cardiol 1989;13:12-18.

36. Kloner RA, Alker KJ. The effect of streptokinase on intramyocardial hemorrhage, infarct size, and the no-reflow phenomenon during coronary reperfusion. Circulation 1984;70:513-21.

37. Johnson WB, Malone SA, Pontedy GA, Anselone CG, Bristow JD. No reflow and extent of infarction during maximum vasodilation in the porcine heart. Circulation 1988;78:462-72. 